\title{
Triptolide inactivates Akt and induces caspase-dependent death in cervical cancer cells via the mitochondrial pathway
}

\author{
MIN JUNG KIM ${ }^{1}$, TAE HWA LEE ${ }^{2}$, SUNG HAN KIM ${ }^{2}$, YEON-JOO CHOI $^{3}$, \\ JEONGHOON $\mathrm{HEO}^{3,4}$ and YOUNG-HO KIM ${ }^{3,4}$ \\ ${ }^{1}$ Shinsegae Women's Hospital; Departments of ${ }^{2}$ Obstetrics and Gynecology, and ${ }^{3}$ Molecular Biology and Immunology, \\ College of Medicine; ${ }^{4}$ Institute for Medical Sciences, Kosin University, Busan, 602-703, Korea
}

Received May 26, 2010; Accepted July 20, 2010

DOI: 10.3892/ijo_00000769

\begin{abstract}
Triptolide, the main active component of the traditional Chinese herbal medicine Tripterygium wilfordii Hook F, has been shown to have potent immunosuppressive and anti-inflammatory properties. Here, we investigated the pro-apoptotic effect of triptolide in human cervical cancer cells and its underlying mechanisms. Exposure of cervical cancer cells to triptolide induced apoptosis, which was accompanied by loss of mitochondrial membrane potential, caspase processing (caspase-8, -9 and -3 ), and cleavage of the caspase substrate, poly(ADP-ribose) polymerase. The cytotoxic effects of triptolide were significantly inhibited by the caspase inhibitor, z-VAD-fmk. Triptolide-induced apoptosis was associated with a marked reduction in Akt phosphorylation and was exacerbated by LY294002 (phosphatidylinositol-3'-kinase inhibitor). Conversely, it was attenuated by Akt overexpression. Triptolide-induced apoptosis was also associated with downregulation of Mcl-1 and was significantly inhibited by Mcl-1 overexpression. These findings show that triptolide induces caspase-dependent, mitochondria-mediated apoptosis in cervical cancer cells, in part, by negatively regulating Akt and Mcl- 1 .
\end{abstract}

\section{Introduction}

Triptolide, a highly oxygenated diterpene isolated from Tripterygium wilfordii Hook F, has been used in traditional Chinese medicine for centuries. Several studies have shown that triptolide has various activities and can function as an immunosuppressor, an anti-cancer drug, and a contraceptive (1-3). In many types of tumor cells, triptolide has been shown to induce apoptosis by promoting the release of cytochrome $\mathrm{c}$

Correspondence to: Dr Young-Ho Kim, Department of Molecular Biology and Immunology, College of Medicine, Kosin University 602-703, Busan, Korea

E-mail:kimyh@kosin.ac.kr

Key words: triptolide, apoptosis, mitochondria, Mcl-1, Akt as a result of mitochondrial damage and by decreasing the expression of anti-apoptotic proteins (4). Apoptosis, a highly regulated form of cell death, is distinguished by the activation of a family of caspases that cleave various proteins, resulting in characteristic morphological and biochemical changes (5-8). Upon induction of apoptosis, several molecules are released from mitochondria into the cytosol, where they perform their pro-apoptotic functions. One such protein is cytochrome c. Upon its release from mitochondria, cytochrome $\mathrm{c}$ binds to the adaptor protein, Apaf-1, leading to Apaf-1 oligomerization and the activation of caspases (i.e., the apoptotic proteases) (9).

A key element of the Bcl-2 mechanism is to control the permeability of the outer membrane of the mitochondria, permitting the release of regulatory factors (e.g., cytochrome c) that are located in the intermembrane space. $\mathrm{Bcl}-2$ family proteins share one or more Bcl-2 homology (BH) domains and are divided into two main groups based on their pro- or anti-apoptotic activities. The anti-apoptotic members include Bcl-2, Bcl-xL and Mcl-1. The pro-apoptotic members can be further classified according to whether they contain multiple $\mathrm{BH}$ domains (e.g., Bax and Bak) or only the $\mathrm{BH} 3$ domain (e.g., Bid and Bim). The $\mathrm{BH} 3$ domain-only proteins require the cooperation of other multidomain family member proteins to induce apoptosis (10-12).

Mcl-1 is unique among anti-apoptotic Bcl-2 homologues because it binds a subset of $\mathrm{BH} 3$ domain-only proteins that are different from those bound by Bcl-2 and Bcl-xL $(13,14)$. In addition, Mcl-1 has been shown to play an apical role in the inhibition of apoptosis following UV irradiation (15). The ability of Mcl-1 to inhibit Bak in the mitochondria suggests that Bak is important for the anti-apoptotic of Mcl-1 (16). However, much less is known about the interaction between Mcl-1 and Bax. Recent studies have revealed that Mcl-1 inhibits the Bax-induced release of cytochrome $\mathrm{c}$ after the conformational change in Bax and its translocation into the mitochondria (17).

In the present study, we investigated the potential therapeutic effects of triptolide and its underlying mechanisms in human cervical cancer. We provide evidence that triptolide induces death in cervical cancer cells through the mitochondrial apoptotic pathway by inactivating Akt and decreasing Mcl-1 expression. 


\section{Materials and methods}

Cell culture and materials. HeLa and Caski cell lines derived from human cervical carcinomas were obtained from the American Type Culture Collection (Manassas, VA, USA). HeLa and Caski cells were cultured in DMEM medium (Gibco BRL, Gaithersburg, MD, USA) containing 10\% fetal bovine serum (FBS) (HyClone, Logan, UT, USA) and $26 \mu \mathrm{M}$ sodium bicarbonate for monolayer cell culture. Stock solutions of triptolide, z-VAD-fmk and LY294002 (Calbiochem, San Diego, CA, USA) were prepared in DMSO. Polyclonal antipolyclonal anti-poly(ADP-ribose) polymerase (PARP), anti$\mathrm{Bc} 1-\mathrm{X}_{\mathrm{L}}$ and anti-actin antibodies were purchased from Santa Cruz Biotechnology (Santa Cruz, CA, USA); anti-phospho Akt, anti-caspase-3 and anti-caspase-9 from Cell Signaling Technology (San Diego, CA, USA). Monoclonal antibodies against caspase- 8 and Bcl-2 were purchased from Upstate Biotechnology (Santa Cruz, CA, USA) and Santa Cruz Biotechnology, respectively.

MTT assay. Cell viability was evaluated using the MTT [3(4,5-dimethylthiazol-2-yl)-2,5-diphenyltetrazolium bromide, a tetrazole] reduction conversion assay. Briefly, cells grown in 96-well plates were treated as required. Next, cells were incubated with $100 \mu \mathrm{l}$ of MTT $(5 \mathrm{mg} / \mathrm{ml})$ for $2 \mathrm{~h}$. The formazan crystals resulting from conversion of MTT by mitochondrial enzymatic activity were solubilized with $\mathrm{Me}_{2} \mathrm{SO}$, and absorbance was measured at $570 \mathrm{~nm}$ using a microplate reader (Molecular Devices, CA, USA). Cell survival was expressed as the absorbance of MTT-treated cells relative to that of untreated controls.

Reverse transcription-polymerase chain reaction ( $R T-P C R)$. Total RNA was extracted from HeLa cells using the TRIzol reagent (Invitrogen, Carlsbad, CA, USA). Complementary DNA was synthesized from $2 \mu \mathrm{g}$ of total RNA using MMLV reverse transcriptase (Takara Co., Ltd. Japan). Human Mcl-1 mRNA was amplified using the sense primer 5'-CCT TCC AAG GAT GGG TTT GT-3' and the antisense primer 5'-TCT TCA ATC AAT GGG GAG CA-3'. The following PCR cycling conditions were used to amplify Mcl-1: $30 \mathrm{sec}$ at $94^{\circ} \mathrm{C}, 45 \mathrm{sec}$ at $58^{\circ} \mathrm{C}, 30 \mathrm{sec}$ at $72^{\circ} \mathrm{C}$ ( 30 cycles), and a 5-min extension at $72^{\circ} \mathrm{C}$. Reaction products were analyzed on a $1.0 \%$ agarose gel and visualized by ethidium bromide (EtBr).

Immunoblot analysis. Proteins were separated by sodium dodecyl sulfate polyacrylamide gel electrophoresis (SDSPAGE) and electrophoretically transferred to nitrocellulose membrane. The nitrocellulose membrane was blocked with $5 \%$ non-fat dry milk in phosphate-buffered saline (PBS)-Tween-20 $(0.1 \%, \mathrm{v} / \mathrm{w})$ at $4^{\circ} \mathrm{C}$ overnight. The membrane was incubated with primary antibody (diluted according to the manufacturer's instructions) for $2 \mathrm{~h}$. Horseradish peroxidase-conjugated anti-rabbit or anti-mouse IgG was used as the secondary antibody. Immunoreactive protein was visualized using enhanced chemiluminescence (Amersham, Arlington Heights, IL, USA). Signals on X-ray film were quantified with a scanning densitometer (Personal Densitometer, Molecular Dynamics, Sunnyvale, CA, USA) using area integration.
DNA fragmentation analysis and 4',6'-diamidino-2phenylindole (DAPI) staining. Approximately $1 \times 10^{6} \mathrm{HeLa}$ cells were lysed in buffer containing $10 \mathrm{mM}$ Tris (pH 7.4), $150 \mathrm{mM} \mathrm{NaCl}, 5 \mathrm{mM}$ EDTA, and $0.5 \%$ Triton $\mathrm{X}-100$ for $30 \mathrm{~min}$ on ice. Lysates were vortexed and cleared by centrifugation at $12,000 \times \mathrm{g}$ for $30 \mathrm{~min}$. Fragmented DNA was extracted from the supernatant with an equal volume of neutral phenol:chloroform:isoamyl alcohol mixture (25:24:1) and separated on a $1.5 \%$ agarose gel containing $0.1 \mu \mathrm{g} / \mathrm{ml}$ EtBr. HeLa cells were treated with triptolide for $24 \mathrm{~h}$. The cells were fixed with $4 \%$ paraformaldehyde on a glass slide for $30 \mathrm{~min}$ at room temperature. Cells were then washed with PBS, incubated with $300 \mathrm{nM}$ DAPI (Microprobe, CA, USA) for $10 \mathrm{~min}$, and examined by fluorescence microscopy. Apoptotic cells were identified by condensation and fragmentation of nuclei. DAPI staining experiments were performed in duplicate.

Flow cytometric analysis of propidium iodide (PI) and JC-1 staining. Approximately $1 \times 10^{6} \mathrm{HeLa}$ cells were suspended in $100 \mu 1$ of PBS and supplemented with $200 \mu 199 \%$ ethanol while being gently vortexed. The cells were incubated at $4^{\circ} \mathrm{C}$ for $1 \mathrm{~h}$, washed with PBS, and resuspended in $250 \mu \mathrm{l}$ of $1.12 \%$ sodium citrate buffer and $12.5 \mu \mathrm{g}$ of RNase. Cells were then incubated at $37^{\circ} \mathrm{C}$ for $30 \mathrm{~min}$. Cellular DNA was stained by incubating cells with $250 \mu 1$ of PI $(50 \mu \mathrm{g} / \mathrm{ml})$ for $30 \mathrm{~min}$ at room temperature. The relative DNA content was then determined based on red fluorescence using fluorescenceactivated cell sorting (FACS), which was performed using a FACScan flow cytometer. For the analysis of apoptosis, HeLa cells were stimulated with triptolide, and apoptosis was measured by flow cytometry following staining with PI. JC-1 is capable of selectively entering the mitochondria, where it forms monomers and emits green fluorescence (FL1) when the mitochondrial membrane potential $(\Delta \psi \mathrm{m})$ is relatively low. At a high $\Delta \psi \mathrm{m}, \mathrm{JC}-1$ aggregates and emits red fluorescence (FL2). The excitation wavelength was set at $488 \mathrm{~nm}$, and the emission of FL1 and FL2 was detected using 525-nm and 575-nm band pass filters, respectively.

Transfection of HeLa cells with Akt, Mcl-1 and Bcl-2 expression vectors. Plasmids encoding human Akt, Mcl-1, or Bcl-2 were a gift from Dr T.K. Kwon (Keimyung University, Korea). Transfections were performed using Lipofectamine Plus reagent (Invitrogen), according to the manufacturer's recommendations. Briefly, $1 \times 10^{5} \mathrm{HeLa}$ cells were cultured in 6-well culture plates in $2 \mathrm{ml}$ of DMEM supplemented with $10 \%$ FBS and incubated for $24 \mathrm{~h}$. Cells were washed twice with Opti-MEM medium (Invitrogen) and incubated for $4 \mathrm{~h}$ in a mixture of $800 \mu \mathrm{l}$ Opti-MEM medium and $200 \mu \mathrm{l}$ Lipofectamine reagent containing $1 \mu \mathrm{g}$ of expression vector (pcDNA 3.1 or Akt, Mcl-1, or Bcl-2 expressing vector). The medium was then replaced with $2 \mathrm{ml}$ of DMEM supplemented with $10 \%$ FBS, and cells were incubated for an additional $24 \mathrm{~h}$. HeLa cells were stably transfected with pcDNA 3.1Bcl-2 plasmids, or control plasmid pcDNA 3.1 vector using Lipofectamine. After $48 \mathrm{~h}$ of incubation, transfected cells were selected in primary cell culture medium containing $700 \mu \mathrm{g} / \mathrm{ml}$ G418. To eliminate the possibility of clonal differences between generated stable cell lines, HeLa/pcDNA 3.1 and 
A
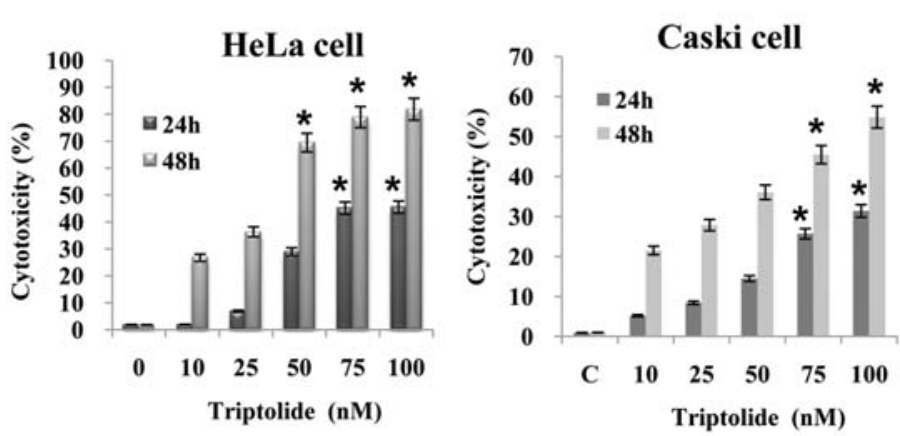

C

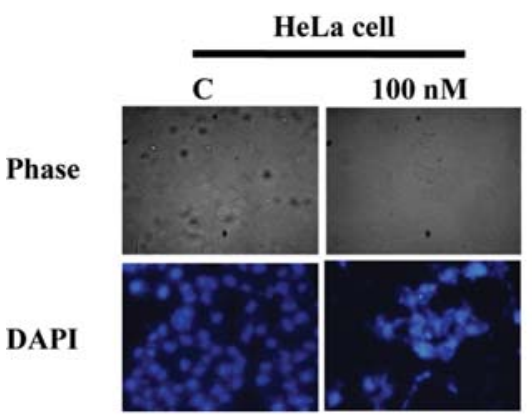

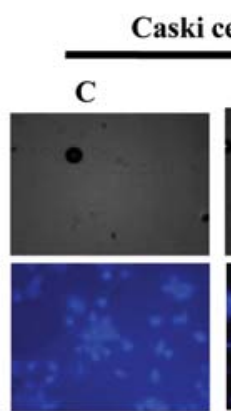

B

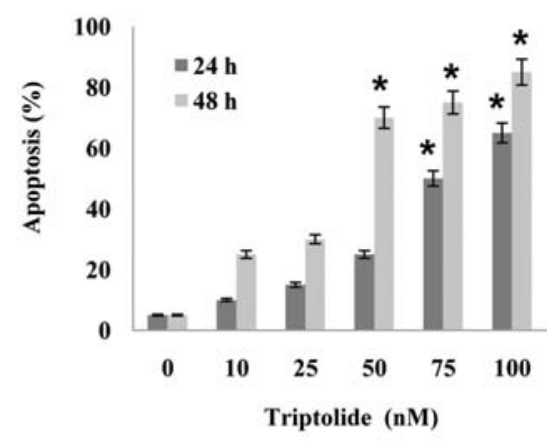

D

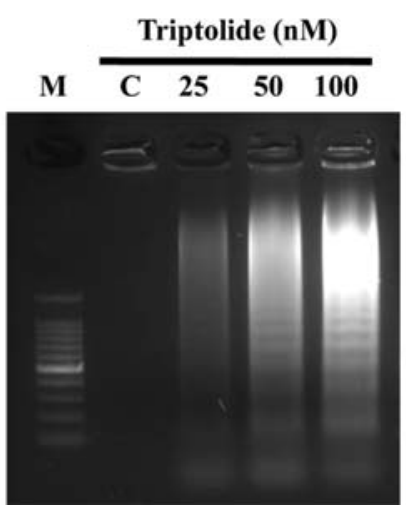

Figure 1. Cytotoxic effect of triptolide cervical cancer cells. (A) MTT assays showing viability of HeLa cells, Caski cells treated for 24 or 48 h with the indicated concentration of triptolide. Cell survival is expressed as the absorbance of MTT-treated cells relative to that of $\mathrm{Me}_{2} \mathrm{SO}_{\text {-treated controls. Data }}$ represent means $\pm \mathrm{SD}(\mathrm{N}=3)$. ${ }^{*} \mathrm{P}<0.05$ compared to the control. (B) The percentage of apoptotic HeLa cells following treatment with the indicated concentrations of triptolide for 24 and $48 \mathrm{~h}$. Apoptosis was assessed by DNA content after propidium iodide staining. Data are reported as the mean \pm SD of three independent experiments. ${ }^{*} \mathrm{P}<0.05$ compared to the control. (C) DAPI staining showing death of cervical cancer cells following exposure to $100 \mathrm{nM}$ triptolide for $24 \mathrm{~h}$. (D) Fragmentation of genomic DNA in HeLa cells treated for $24 \mathrm{~h}$ with the indicated concentrations of triptolide. Fragmented DNA was extracted and analyzed on a $2 \%$ agarose gel. C, control; $\mathrm{M}$, marker.

$\mathrm{HeLa} / \mathrm{Bcl}-2$ clones were tested for Bcl-2 expression by immunoblotting after 3 or 4 weeks, and employed in subsequent experiments.

Analysis of cytochrome c release. Cells were harvested, washed once with ice-cold PBS, and gently lysed for $10 \mathrm{~min}$ in $60 \mu 1$ of ice-cold lysis buffer (25 mM HEPES, $\mathrm{pH} 7.5$; $250 \mathrm{mM}$ sucrose; $1 \mathrm{mM}$ EDTA; 1 mM EGTA; $1 \mathrm{mM}$ DTT; $10 \mathrm{mM} \mathrm{KCl} ; 1.5 \mathrm{mM} \mathrm{MgCl}$; $1 \mathrm{mM}$ PMSF; protease inhibitor cocktail). Lysates were centrifuged at 12,000 rpm for $20 \mathrm{~min}$ at $4^{\circ} \mathrm{C}$ to obtain supernatants (cytosolic extracts free of mitochondria) and pellets (fraction that contains mitochondria). The resulting cytosolic fractions were analyzed by immunoblot using an anti-cytochrome c antibody.

Statistical analysis. Experiments were performed three or more separate times. Statistical analysis was performed using the Student t-test or analysis of variance. $\mathrm{P}<0.05$ was considered significant.

\section{Results}

Induction of apoptosis by triptolide in cervical cancer cells. To verify that triptolide is cytotoxic, we analyzed the viability of human cervical cancer cells exposed to varying doses of triptolide. MTT assays revealed that treatment with triptolide for 24 and $48 \mathrm{~h}$ reduced the viability of HeLa and Caski cells in a concentration-dependent manner (Fig. 1A). To understand whether triptolide decreased cell viability by inducing apoptosis, we used two established criteria to assess apoptosis in our system, flow cytometric analysis of PI staining and analysis of DNA fragmentation. Flow cytometric analysis revealed that treatment of HeLa cells with triptolide markedly increased accumulation of sub-G1-phase cells in a concentration- and time-dependent manner (Fig. 1B). DNA fragmentation, another hallmark of apoptosis, was also increased by triptolide. In addition, triptolide markedly increased nuclear condensation and the formation of apoptotic bodies in both HeLa and Caski cells, as seen by DAPI staining (Fig. 1C). As shown in Fig. 1D, agarose gel electrophoresis of DNA from HeLa cells treated with triptolide for $24 \mathrm{~h}$ produced a typical ladder-like pattern of internucleosomal fragmentation. These results suggest that the cytotoxic effect of triptolide on cervical cancer cells is related to its apoptosisinducing activity.

Effect of triptolide on caspase processing. Next, we investigated the possible molecular and cellular mechanisms 
A

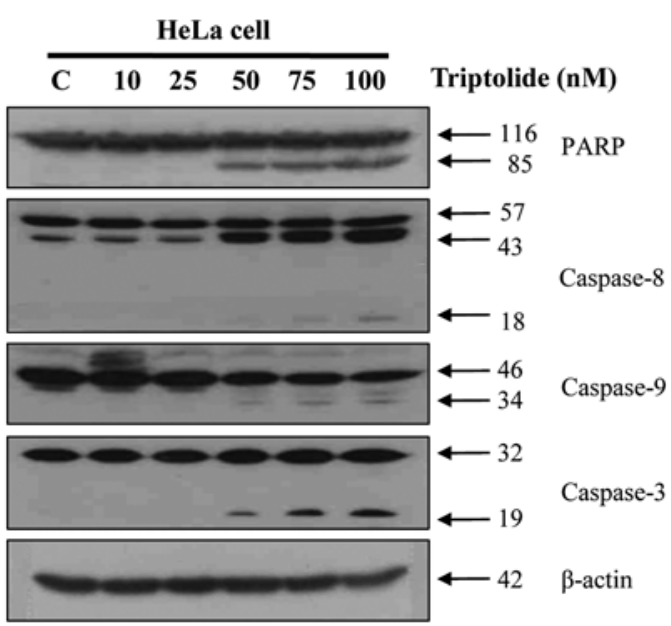

B

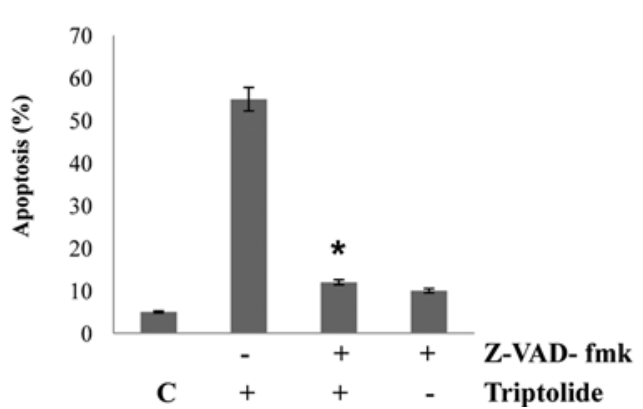

Caski cell

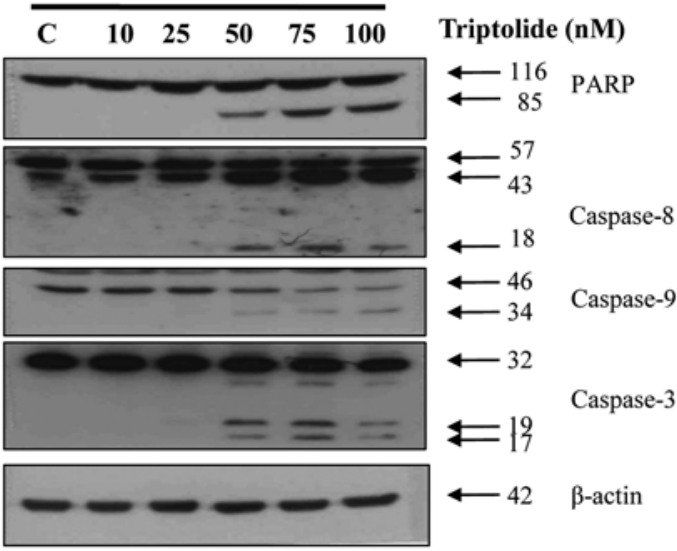

C

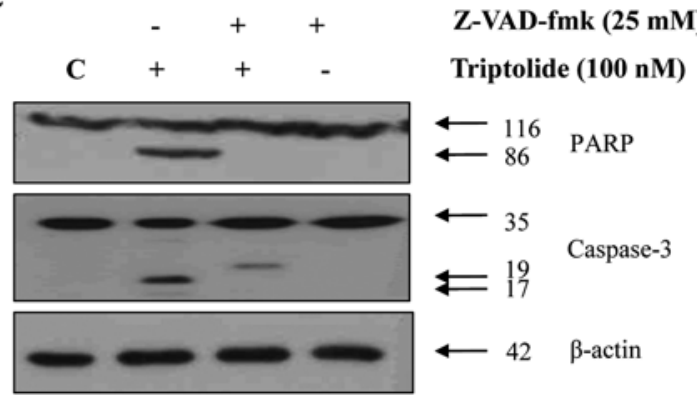

Figure 2. Effect of triptolide on caspase activation in cervical cancer cells. (A) Immunoblot analysis of caspase-8, caspase-9, caspase-3 and PARP in HeLa, Caski lysates $(20 \mu \mathrm{g})$. Proteolytic fragments of the caspases and PARP are indicated with arrows. B-actin served as a loading control. (B) Apoptosis in HeLa cells incubated with $25 \mu \mathrm{M} \mathrm{z}$-VAD-fmk or solvent for $1 \mathrm{~h}$ before treatment with $100 \mathrm{nM}$ triptolide for $1 \mathrm{~h}$. Apoptosis was assessed by the DNA content after propidium iodide staining. Data are expressed as the mean ( \pm standard deviation) obtained from three independent experiments. (C) Immunoblot analysis showing the effect of z-VAD-fmk on the cleavage of PARP and caspase-3. B-actin served as a loading control.

underlying triptolide-induced apoptosis in cervical cancer cells. Because caspases participate in tumor cell death, we examined the effect of triptolide on the activation of caspases in cervical cancer cells. We found that both pro-caspase- 8 and pro-caspase- 9 were cleaved in HeLa and Caski cells treated with 50-100 $\mathrm{nM}$ of triptolide for $24 \mathrm{~h}$. The same was true of caspase- 3 , which lies downstream of caspase- 8 and caspase-9. The activation of caspases often leads to the proteolytic cleavage of target proteins, such as PARP. Immunoblot analysis showed that increasing concentrations of triptolide progressively increased the proteolytic cleavage of PARP in HeLa and Caski cells (Fig. 2A). To further evaluate caspase activation in triptolide-treated cells, we treated HeLa cells with a general, potent caspase inhibitor (z-VAD-fmk). As shown in Fig. 2B and C, triptolide-induced cell death was significantly suppressed when cells were pre-treated with z-VAD-fmk, indicating that triptolideinduced apoptosis is mediated by caspase- 3 activation. These results clearly show that triptolide-induced apoptosis is associated with the activation of caspases.

Effect of triptolide on Bcl-2 family proteins in cervical cancer cells. Members of the Bcl-2 family, including Bcl-2 and Mcl-1, are anti-apoptotic proteins that favor the growth of cancer cells (18-20). In view of the critical role that Bcl-2 family proteins play in the regulation of apoptosis, we examined the expression of $\mathrm{Bcl}-2$ proteins in cervical cancer cells treated with varying concentrations (0-100 nM) of triptolide for varying lengths of time $(0-24 \mathrm{~h})$. Treatment of HeLa cells with triptolide was not changed the expression of Bcl-2, Bcl-xL and Bax proteins (Fig. 3A). However, treatment of cervical cancer cells with the indicated concentration (10-100 $\mathrm{nM})$ of triptolide at the indicated times (0-24 h) of triptolide markedly decreased levels of Mcl-1 (Fig. 3B). To determine whether triptolide decreased Mcl-1 protein levels through changes in transcription, we analyzed Mcl-1 mRNA levels using RT-PCR. Indeed, we found that Mcl-1 mRNA levels decreased in a manner dependent on the dose of triptolide (Fig. 3C). Actin mRNA levels were unaffected by triptolide treatment. These data strongly suggest that triptolide-induced downregulation of Mcl-1 expression is controlled at the transcriptional level.

Effect of triptolide on Akt phosphorylation in HeLa cells. The protein kinase, Akt, participates in cell proliferation, survival and transformation (21). Therefore, we investigated the effect of triptolide on Akt phosphorylation in HeLa cells. As shown in Fig. 4, HeLa cells expressed substantial levels of endogenous phosphorylated Akt, suggesting that Akt is constitutively activated in these cells. We observed a profound decrease in the amount of phosphorylated Akt in HeLa cells treated with $>25 \mathrm{nM}$ triptolide. Triptolide attenuated the 
A

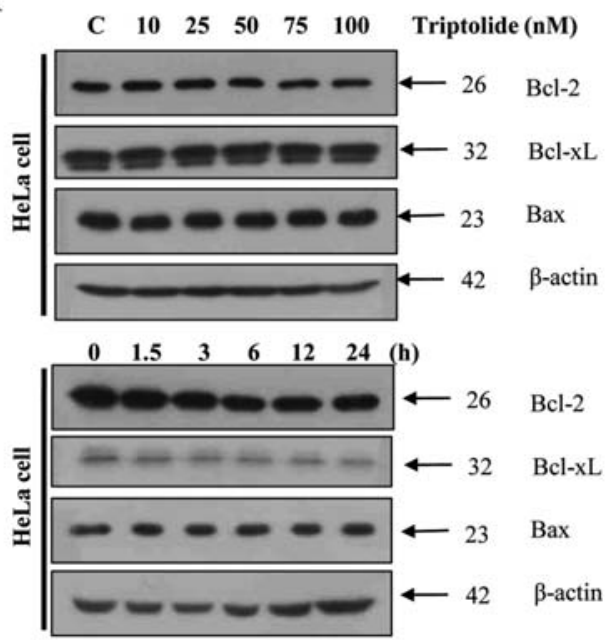

C

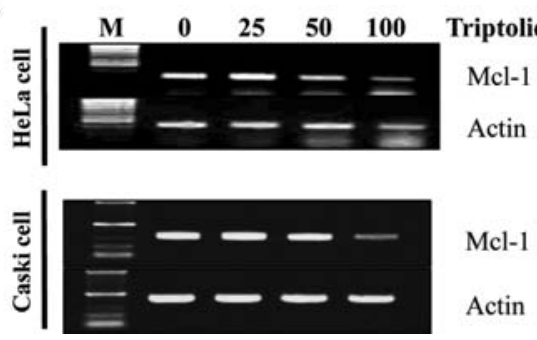

B
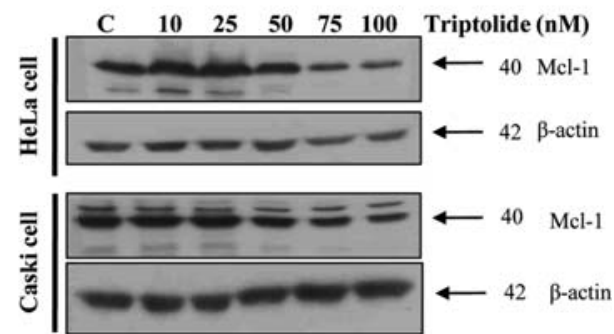

$\begin{array}{lllllll}0 & 1.5 & 3 & 6 & 12 & 24 & (\mathrm{~h})\end{array}$

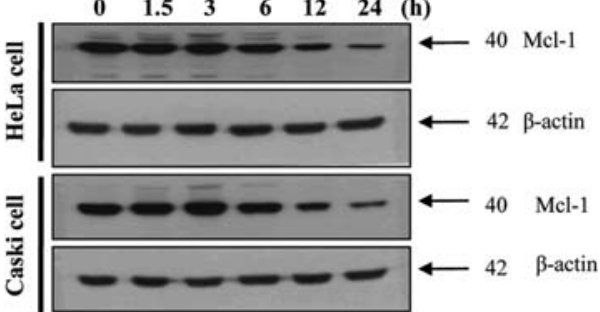

Figure 3. Effect of triptolide on Bcl-2 family proteins in cervical cancer cells. (A and B) Immunoblot analysis of Bcl-2, Bcl-xL and Bax (A) as well as Mcl-1 (B) in lysates $(20 \mu \mathrm{g})$ from HeLa cells incubated with the indicated concentration of triptolide for $24 \mathrm{~h}$ or with $100 \mathrm{nM}$ triptolide for the indicated time. B-actin served as a loading control. (C) RT-PCR analysis of Mcl-1 mRNA levels in HeLa and Caski cells incubated for $24 \mathrm{~h}$ with the indicated concentrations of triptolide. $\beta$-actin mRNA served as the control.

A
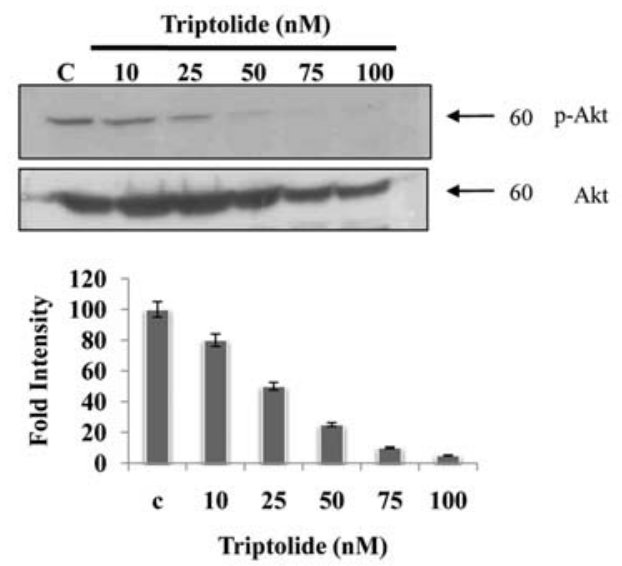

C

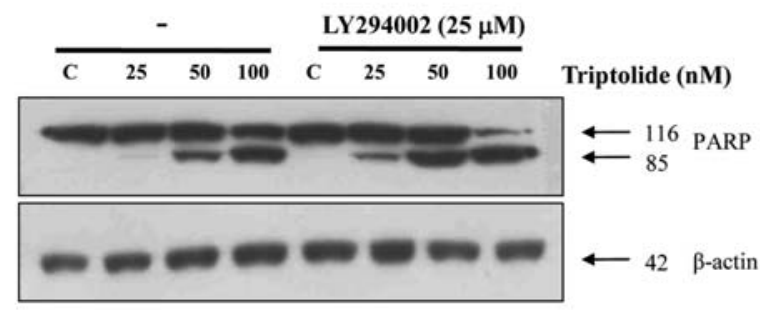

B

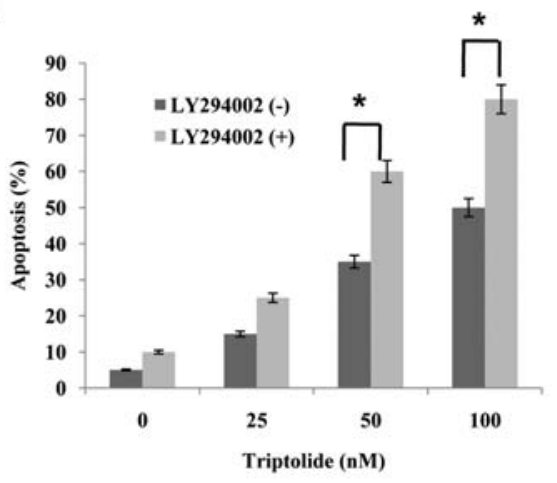

D

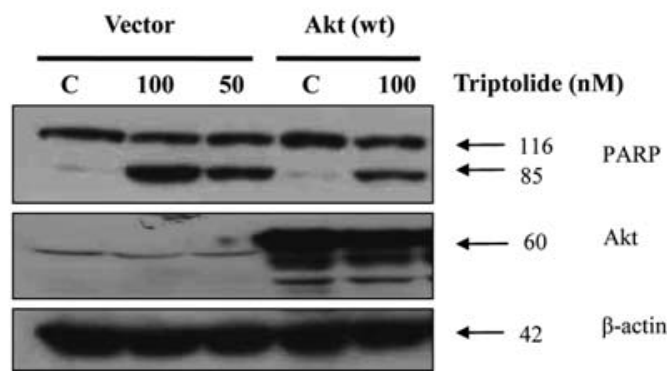

Figure 4. Effect of triptolide on PI3K/Akt signaling in HeLa cells. (A) Immunoblot analysis of phospho-Akt and Akt in HeLa cells exposed to the indicated concentrations of triptolide for $24 \mathrm{~h}$. In the bar graph, the Y-axis is the intensity of p-Akt/Akt. (B) Apoptosis in HeLa cells treated for $24 \mathrm{~h}$ with the indicated concentrations of triptolide with or without $25 \mu \mathrm{M}$ LY294002. Apoptosis was assessed by DNA content after propidium iodide staining. ${ }^{*} \mathrm{P}<0.05$ compared to LY294002(-) cells. (C) Immunoblot analysis showing the effect of LY294002 on PARP cleavage. B-actin served as a loading control. (D) Immunoblot analysis of PARP Akt and B-actin in HeLa cells transfected with empty vector or Akt (wt) and then treated with or without triptolide for $24 \mathrm{~h}$. 
A

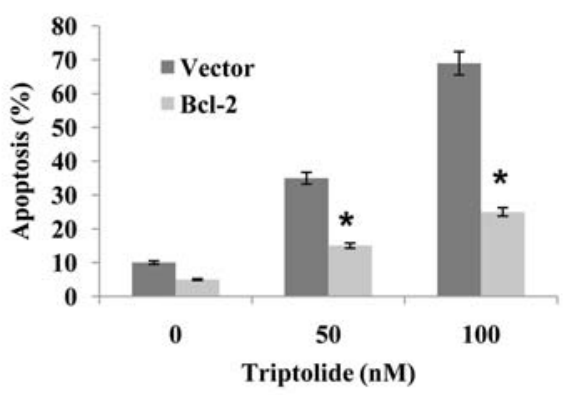

C

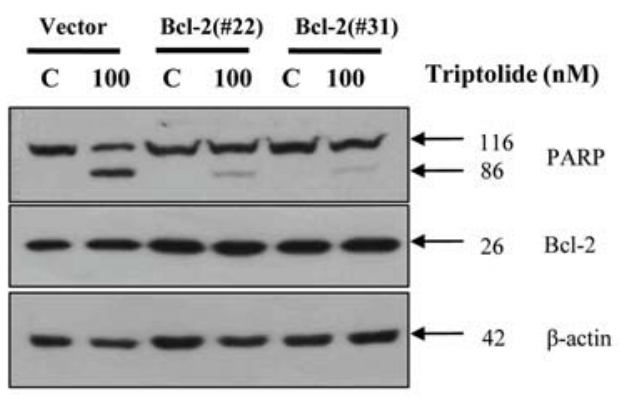

B

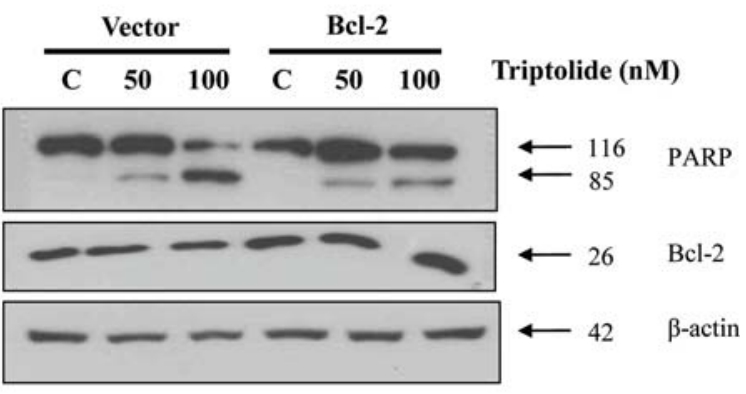

D

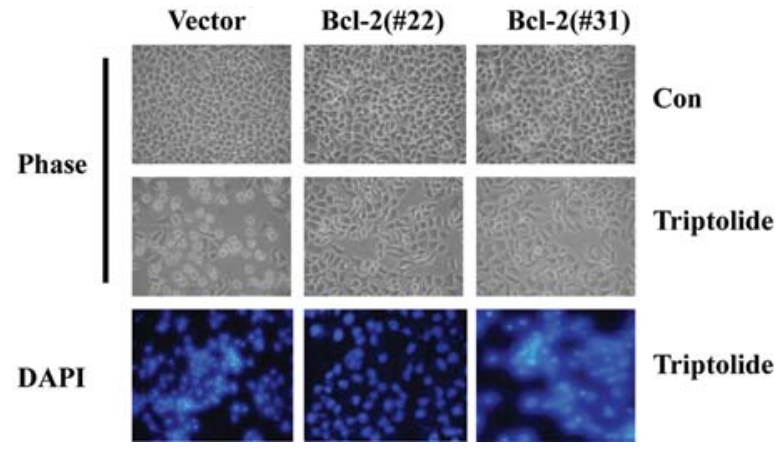

Figure 5. Effect of Bcl-2 overexpression on triptolide-induced death in cervical cancer cells. (A) Apoptosis in HeLa cells transfected with pcDNA (HeLa/vector) or Bcl-2 (HeLa/Bcl-2) and then treated with the indicated concentrations of triptolide for 24 h. Apoptosis was assessed by DNA content after propidium iodide staining. Data represent means $\pm \mathrm{SD}(\mathrm{N}=3)$. ${ }^{*} \mathrm{P}<0.05$ versus vector. (B) Immunoblot analysis of Bcl-2, PARP and $\beta$-actin in HeLa/vector and HeLa/Bcl-2 cells exposed to the indicated concentrations of triptolide for $24 \mathrm{~h}$. (C) Immunoblot analysis of Bcl-2, PARP and B-actin in cell lines that stably expressed Bcl-2 (HeLa/Bcl-2 no. 22 and HeLa/Bcl-2 no. 31). Cells were exposed to 100 nM triptolide for 24 h. (D) DAPI staining showing resistance of HeLa/Bcl-2 no. 22 and HeLa/Bcl-2 no. 31 cells to death following exposure to $100 \mathrm{nM}$ triptolide for $24 \mathrm{~h}$.

ability to phosphorylate Akt in HeLa cells. Importantly, PI staining (Fig. 4B) and immunoblot analysis of PARP cleavage (Fig. 4C) showed that triptolide-mediated apoptosis was exacerbated by LY294002, an inhibitor of the Aktactivating kinase, PI3K. This suggests that triptolide induce apoptosis by negatively regulating Akt. This idea was tested by analyzing the effect of Akt overexpression on triptolideinduced apoptosis in HeLa cells. We found that apoptosis, as assessed by PARP cleavage, occurred less frequently in HeLa cells expressing ectopic Akt than in vector-transfected HeLa cells (HeLa/vector cells). Together, these results suggest that downregulation of PI3K/Akt signaling plays an important role in triptolide-induced apoptosis in cervical cancer cells.

Effect of Bcl-2 overexpression on triptolide-induced death in HeLa cells. To investigate the role of Bcl-2 in triptolidemediated apoptosis, we analyzed triptolide cytotoxicity (50 or $100 \mathrm{nM}$ triptolide for $24 \mathrm{~h}$ ) in HeLa cells overexpressing Bcl-2 (HeLa/Bcl-2 cells). FACS analysis of PI staining revealed that triptolide treatment markedly decreased the accumulation of sub-G1 phase cells in $\mathrm{HeLa} / \mathrm{Bcl}-2$ cells but not in $\mathrm{HeLa} /$ vector cells (Fig. 5A). Triptolide also increased cell death, as seen by a lower level of PARP cleavage in HeLa/Bcl-2 cells than in HeLa/vector cells (Fig. 5B). To further quantify apoptosis induced by triptolide, we analyzed PARP cleavage (Fig. 5C) as well as nuclear condensation and fragmentation (Fig. 5D) in cell lines stably overexpressing Bcl-2 (HeLa/Bcl-2 no. 22 and HeLa/Bcl-2 no. 31). We found that $\mathrm{HeLa} /$ vector cells treated with $100 \mathrm{nM}$ triptolide exhibited nuclear condensation and the formation of apoptotic bodies, as seen by DAPI staining. In contrast, chromatin was rarely condensed and fragmented in triptolide-treated HeLa/ Bcl-2 no. 22 cells or HeLa/Bcl-2 no. 31 cells.

Triptolide-induced activation of the mitochondrial cell death pathway in HeLa cells. To understand which of the apoptotic signaling pathways is essential for triptolide-induced caspasedependent cell death, we explored whether triptolide-induced cell death requires caspase-9, which is activated through the mitochondrial signaling pathway for cell death. To do this, we transiently transfected HeLa cells with plasmid encoding dominant-negative caspase- 9 (caspase- $9 \mathrm{dN}$ ) and treated these cells with triptolide for $24 \mathrm{~h}$. As shown in Fig. 6A, caspase- $9 \mathrm{dN}$ cells, but not vector-transfected cells, were resistant to triptolide, suggesting that caspase- 9 is essential for triptolide-induced cell death and that triptolide induces apoptosis via the mitochondrial pathway. To further show that triptolide-induced cell death occurs via the mitochondrial pathway, we measured cytochrome c release and $\Delta \psi \mathrm{m}$ in 
A

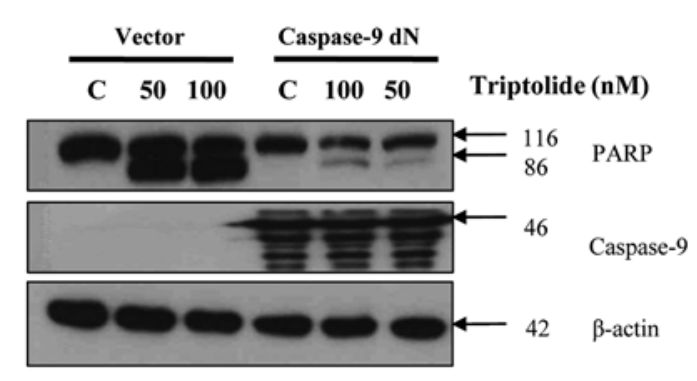

C
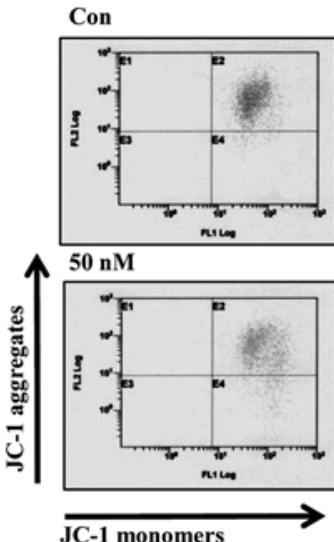

$25 \mathrm{nM}$

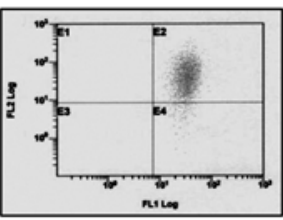

$100 \mathrm{nM}$

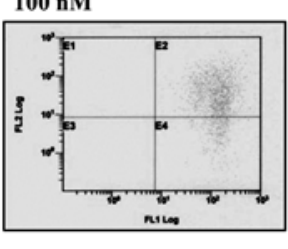

B

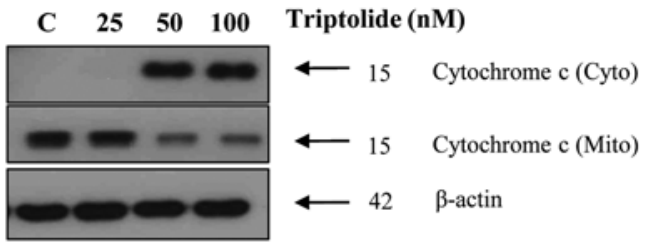

D

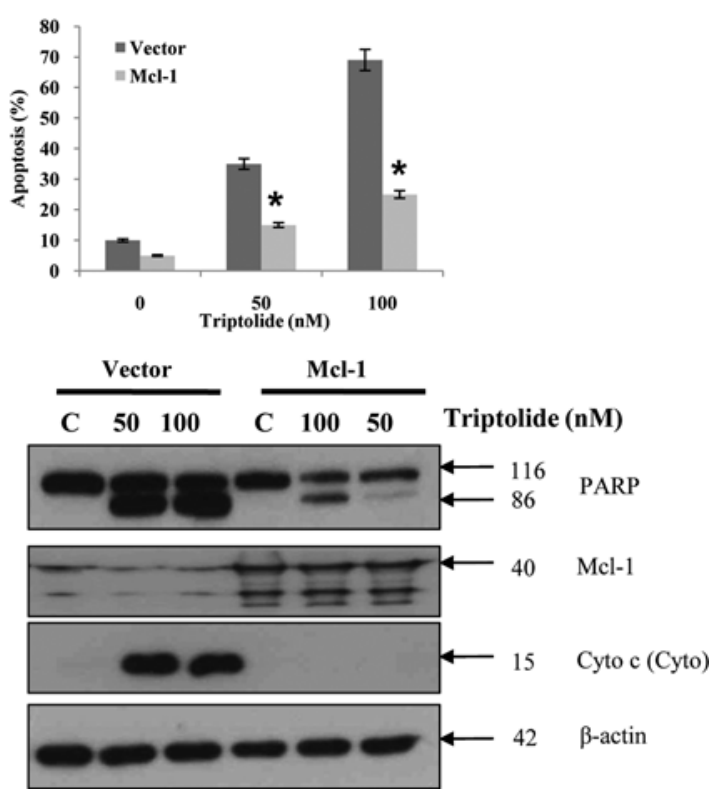

Figure 6. Induction of mitochondrial apoptotic events by triptolide in HeLa cells. (A) Immunoblot analysis of caspase-9 in HeLa cells that were transfected with pcDNA (vector) or caspase- $9 \mathrm{dN}$ and treated with or without triptolide for $24 \mathrm{~h}$. (B) Immunoblot analysis of cytochrome c in cells treated with triptolide for $24 \mathrm{~h}$. (C) Flow cytometric analysis of $\Delta \psi \mathrm{m}$ in cells treated with the indicated concentration of triptolide. $\Delta \psi \mathrm{m}$ was determined with JC-1. (D) HeLa cells that were transfected with pcDNA (HeLa/vector) or Mcl-1 (HeLa/Mcl-1) were treated with or without triptolide for 24 h. PARP, Mcl-1, cytochrome c and $\beta$-actin levels were determined by immunoblot, and apoptosis was determined by DNA content (PI staining). Data represent means $\pm \mathrm{SD}(\mathrm{N}=3)$. ${ }^{*} \mathrm{P}<0.05$ versus vector.

HeLa cells. We were unable to detect cytochrome c levels in the cytosol of untreated cells; however, cytochrome c was greatly increased in the cytosol of cells treated with triptolide (50 or $100 \mathrm{nM}$ ) (Fig. 6B). Furthermore, $\Delta \psi \mathrm{m}$ was substantially decreased in cells exposed to triptolide (50 or $100 \mathrm{nM}$ ) (Fig. 6C). Finally, we hypothesized that if triptolide-induced cell death is indeed mediated through inactivation of Mcl-1, then Mcl-1 levels will determine the extent to which triptolide induces cell death. To test this idea, we investigated the effect of Mcl-1 overexpression on triptolide-induced death of HeLa cells. As expected, triptolide induced considerable death in HeLa/vector cells (Fig. 6D), as assessed by PI staining, PARP cleavage and cytochrome c release. However, cell death was attenuated by Mcl-1 overexpression. Together, our findings support the idea that triptolide induces apoptosis through the mitochondrial pathway and that elimination of Mcl-1 by triptolide promotes mitochondrial injury.

\section{Discussion}

Many efforts have been made in the therapeutic application of triptolide in chemoprevention. In our study, triptolide induced apoptosis in HeLa and Caski cervical cancer cells. Our data suggest that the apoptotic effect of triptolide on cervical cancer cells may result from the modulation of activities and/or the expression of multiple cellular factors, including caspases, Bcl-2, Mcl-1 and Akt. Our investigation of the underlying apoptotic signaling pathway in cervical cancer cells yielded two important findings. First, we found that triptolide-induced death of cervical cancer cells was dependent on Akt inactivation and caspase-9 activation. Secondly, we identified Mcl-1 as an anti-apoptotic factor upstream of the mitochondria that plays a central role in countering the apoptosis pathway initiated by triptolide.

The PI3K/Akt pathway is a well-characterized signaling pathway that blocks apoptosis in a variety of cell types (22). Interestingly, overexpression of PI3K/Akt is observed in cancer cells, and increased PI3K/Akt signaling in cancer cells is thought to impart resistance to anti-cancer drugs (23). In this study, we found that HeLa cells contained substantial levels of phosphorylated Akt (Fig. 4A). Therefore, sustained Akt activity in these cells may facilitate their growth and/or survival. Triptolide has been shown to enhance PS-341 (bortezomib, proteasome inhibitor)-induced apoptosis via the $\mathrm{PI} 3 \mathrm{~K} / \mathrm{Akt} /$ nuclear factor- $\mathrm{KB}$ pathway in dexamethasoneresistant human multiple myeloma cells (24). Moreover, triptolide leads to the inactivation of the PI3K/Akt pathway in drug-resistant chronic myelogenous leukemia cells (25). However, we found that triptolide had an inhibitory effect on Akt in HeLa cells (Fig. 4). Because Akt is a pro-survival 
protein, the inhibition of Akt may be involved in triptolidemediated growth suppression of HeLa cells.

A variety of cellular proteins participate in the induction of apoptosis. Among these are the caspases, which are essential for the execution of cell death induced by apoptotic stimuli (26). We have demonstrated that triptolide exposure leads to the processing of caspase- $8,-9$ and -3 in cervical cancer cells (Fig. 2). An important finding was that triptolide induced caspase- 3 processing and PARP cleavage in parallel with the induction of apoptosis. Furthermore, the inhibition of caspase- 3 by the broad-spectrum caspase inhibitor zVAD-fmk blocked cell death by triptolide, suggesting that triptolide-induced cell death is caspase-dependent (Fig. 2B and C). Triptolide has been reported to induce caspasedependent apoptosis in leukemia cells by degrading XIAP (4). However, XIAP protein was less affected by triptolide in cervical cancer cells.

The finding that transfection of caspase- $9 \mathrm{dN}$ imparted resistance to triptolide indicates that the activation of caspase- 9 and subsequent activation of caspase- 3 activation (i.e., the mitochondrial pathway of caspase activation) are critical to the action of triptolide (Fig. 6A). The release of mitochondrial intermembrane space proteins to the cytosol is a key event during apoptosis $(27,28)$. Release of cytochrome $\mathrm{c}$ is required for the initiation of the apoptosome formation and the activation of caspases, while Smac/DIABLO and Omi/HtrA2 are believed to enhance caspase activation through the neutralization of the inhibitors of apoptosis proteins. Our results clearly showed that triptolide induced cytochrome c release into the cytosol (Fig. 6B) and decreased $\Delta \psi \mathrm{m}$ (Fig. 6C), supporting the idea that triptolide activates the mitochondrial apoptotic pathway.

Members of the Bcl-2 family, including Bcl-2 and Mcl-1, negatively regulate apoptosis and caspase activation by modulating mitochondrial membrane integrity (18-20). We observed that triptolide-induced apoptosis occurred through the inhibition of Mcl-1, with this event being followed by a loss of $\Delta \psi \mathrm{m}$ and activation of the cytochrome c/caspase-9 pathway. These observations are consistent with previous studies showing that triptolide induces cytochrome c release, which causes apoptosis through activation of caspases (4). Here, triptolide effectively inhibited Mcl-1 expression at both the protein and mRNA levels (Fig. 3B and C, respectively). Several studies have implicated E2F1, CREB and ETS transcription factors in the control of Mcl-1 gene expression (29-31). Our finding that triptolide substantially decreased Mcl-1 mRNA levels suggests that triptolide downregulates Mcl-1 expression by repressing promoter activity or destabilizing mRNA.

Here, we found that forced expression of Mcl-1 markedly diminished triptolide-mediated death in HeLa cancer cells. This finding has important therapeutic implications, as it shows that the downregulation of Mcl-1 plays a critical role in triptolide-induced lethality. In accord with our finding, Mcl-1 overexpression also largely inhibited PARP cleavage and the release of cytochrome $\mathrm{c}$ into the cytosol. These findings are consistent with the studies described by Nijhawan and colleagues (15), who demonstrated that Mcl-1 operates upstream of Bax and Bcl-xL translocation to the mitochondria, cytochrome $\mathrm{c}$ release and caspase activation in
UV-treated HeLa cells. Interestingly, in our study, a decrease in Mcl-1 protein alone was not sufficient to induce apoptosis, suggesting that one or more additional perturbations are necessary for triptolide-induced cell death. Another study showed that Mcl-1 interacts with tBid and impairs the ability of tBid to induce the release of cytochrome $\mathrm{c}$ and apoptosis (32). Recently, two separate groups used BH3 peptides to show that BH3-only proteins can differentially target antiapoptotic Bcl-2 proteins $(13,14)$.

In summary, triptolide induces apoptosis in cervical cancer cells, likely by inducing multiple cellular events such as caspase activation, Mcl-1 inactivation, inhibition of Akt signaling, and loss of $\Delta \psi \mathrm{m}$. The findings presented here suggest that triptolide is a potential anti-cancer drug for cervical cancer.

\section{Acknowledgements}

This work was supported by grant of Kosin University College of Medicine (2008).

\section{References}

1. Zhen QS, Ye X and Wei ZJ: Recent progress in research on Tripterygium: a male antifertility plant. Contraception 51 : 121-129, 1995.

2. Tengchaisri T, Chawengkirttikul R, Rachaphaew N, Reutrakul V, Sangsuwan R and Sirisinha S: Antitumor activity of triptolide against cholangiocarcinoma growth in vitro and in hamsters. Cancer Lett 133: 169-175, 1998.

3. Hachida M, Lu H, Zhang X, Saito S, Furutani Y, Matsuoka R, Hoshi $\mathrm{H}$ and Koyanagi $\mathrm{H}$ : Inhibitory effect of triptolide on platelet derived growth factor-A and coronary arteriosclerosis after heart transplantation. Transplant Proc 7: 2719-2723, 1999.

4. Carter BZ, Mak DH, Schober WD, McQueen T, Harris D, Estrov Z, Evans RL and Andreeff M: Triptolide induces caspase-dependent cell death mediated via the mitochondrial pathway in leukemic cells. Blood 108: 630-637, 2006.

5. Cohen JJ: Apoptosis. Immunol Today 14: 126-130, 1993.

6 . White E: Life, death, and the pursuit of apoptosis. Genes Dev 10: 1-15, 1996.

7. Williams GT and Smith CA: Molecular regulation of apoptosis: genetic controls on cell death. Cell 74: 777-779, 1993.

8. Wyllie AH, Kerr JF and Currie AR: Cell death: the significance of apoptosis. Int Rev Cytol 68: 251-306, 1980.

9. Danial NN and Korsmeyer SJ: Cell death: critical control points. Cell 116: 205-219, 2004.

10. Desagher S, Osen-Sand A, Nichols A, Eskes R, Montessuit S, Lauper S, Maundrell K, Antonsson B and Martinou JC: Bidinduced conformational change of $\mathrm{Bax}$ is responsible for mitochondrial cytochrome $\mathrm{c}$ release during apoptosis. J Cell Biol 144: 891-901, 1999.

11. Wei MC, Zong WX, Cheng EH, Lindsten T, Panoutsakopoulou V, Ross AJ, Roth KA, MacGregor GR, Thompson CB and Korsmeyer SJ: Proapoptotic BAX and BAK: a requisite gateway to mitochondrial dysfunction and death. Science 292: 727-730, 2001.

12. Zong WX, Lindsten T, Ross AJ, MacGregor GR and Thompson CB: BH3-only proteins that bind pro-survival Bcl-2 family members fail to induce apoptosis in the absence of Bax and Bak. Genes Dev 15: 1481-1486, 2001.

13. Chen L, Willis SN, Wei A, Smith BJ, Fletcher JI, Hinds MG, Colman PM, Day CL, Adams JM and Huang DC: Differential targeting of prosurvival $\mathrm{Bcl}-2$ proteins by their $\mathrm{BH} 3$-only ligands allows complementary apoptotic function. Mol Cell 17: 393-403, 2005.

14. Kuwana T, Bouchier-Hayes L, Chipuk JE, Bonzon C, Sullivan BA, Green DR and Newmeyer DD: BH3 domains of BH3-only proteins differentially regulate Bax-mediated mitochondrial membrane permeabilization both directly and indirectly. Mol Cell 17: 525-535, 2005. 
15. Nijhawan D, Fang M, Traer E, Zhong Q, Gao W, Du F and Wang X: Elimination of Mcl-1 is required for the initiation of apoptosis following ultraviolet irradiation. Genes Dev 17: 1475-1486, 2003.

16. Willis SN, Chen L, Dewson G, Wei A, Naik E, Fletcher JI, Adams JM and Huang DC: Proapoptotic Bak is sequestered by Mcl-1 and Bcl-xL, but not Bcl-2, until displaced by BH3-only proteins. Genes Dev 19: 1294-1305, 2005.

17. Germain M, Milburn J and Duronio V: MCL-1 inhibits BAX in the absence of MCL-1/BAX Interaction. J Biol Chem 283: 6384-6392, 2008.

18. Adams JM and Cory S: The Bcl-2 protein family: arbiters of cell survival. Science 281: 1322-1326, 1998.

19. Zhang B, Gojo I and Fenton RG: Myeloid cell factor-1 is a critical survival factor for multiple myeloma. Blood 99: 1885-1893, 2002.

20. Festjens N, van Gurp M, van Loo G, Saelens X and Vandenabeele P: Bcl-2 family members as sentinels of cellular integrity and role of mitochondrial intermembrane space proteins in apoptotic cell death. Acta Haematologica 111: 7-27, 2004.

21. Yoeli-Lerner $\mathrm{M}$ and Toker A: Akt/PKB signaling in cancer: a function in cell motility and invasion. Cell Cycle 5: 603-605, 2006.

22. Song G, Ouyang G and Bao S: The activation of Akt/PKB signaling pathway and cell survival. J Cell Mol Med 9: 59-71, 2005.

23. McCubrey JA, Steelman LS, Abrams SL, Lee JT, Chang F, Bertrand FE, Navolanic PM, Terrian DM, Franklin RA, D'Assoro AB, Salisbury JL, Mazzarino MC, Stivala F and Libra M: Roles of the RAF/MEK/ERK and PI3K/PTEN/AKT pathways in malignant transformation and drug resistance. Adv Enzyme Regul 46: 249-279, 2006.
24. Yang M, Huang J, Pan HZ and Jin J: Triptolide overcomes dexamethasone resistance and enhanced PS-341-induced apoptosis via PI3k/Akt/NF-kappaB pathways in human multiple myeloma cells. Int J Mol Med 22: 489-496, 2008.

25. Shi X, Jin Y, Cheng C, Zhang H, Zou W, Zheng Q, Lu Z, Chen Q, Lai Y and Pan J: Triptolide inhibits Bcr-Abl transcription and induces apoptosis in STI571-resistant chronic myelogenous leukemia cells harboring T315I mutation. Clin Cancer Res 15: 1686-1697, 2009

26. Cohen GM: Caspases: the executioners of apoptosis. Biochem J 326: 1-16, 1997.

27. Fulda S and Debatin KM: Apoptosis signaling in tumor therapy. Ann NY Acad Sci 1028: 150-156, 2004.

28. Fulda S and Debatin KM: Targeting apoptosis pathways in cancer therapy. Curr Cancer Drug Targets 4: 569-576, 2004.

29. Croxton R, Ma Y, Song L, Haura EB and Cress WD: Direct repression of the Mcl-1 promoter by E2F1. Oncogene 21: 1359-1369, 2002

30. Wang JM, Lai MZ and Yang-Yen HF: Interleukin-3 stimulation of mcl-1 gene transcription involves activation of the PU.1 transcription factor through a p38 mitogen-activated protein kinase-dependent pathway. Mol Cell Biol 23: 1896-1909, 2003.

31. Wang JM, Chao JR, Chen W, Kuo ML, Yen JJ and Yang-Yen HF: The antiapoptotic gene mcl-1 is up-regulated by the phosphatidylinositol 3-kinase/Akt signaling pathway through a transcription factor complex containing CREB. Mol Cell Biol 19: 6195-6206, 1999.

32. Clohessy JG, Zhuang J, de Boer J, Gil-Gómez G and Brady HJ: Mcl-1 interacts with truncated Bid and inhibits its induction of cytochrome c release and its role in receptor-mediated apoptosis. J Biol Chem 281: 5750-5759, 2006. 